\title{
Building Beyond the Crisis: an Analysis of Post COVID-19 Concrete Construction
}

\author{
Varenya Kaushik \\ Civil Department, SRM University, \\ Delhi NCR, INDIA
}

\begin{abstract}
This paper talks about COVID-19 and its impact on concrete construction. Coronavirus disease (COVID-19) is an infectious disease caused by a newly discovered coronavirus. This pandemic has brought a lot of changes in the concrete construction industry like the cleanliness and safety of the job is going to increase to a very high level. The demand of projects would also change as the demand for hospitals is increasing at a rapid rate. Social distancing is going to be a key factor against COVID-19. There would be an increase in online work to maintain social distancing and the duration of projects may also increase due to decrease in production of concrete. There are certain norms set up by the government to fight against COVID19. The World Health Organisation (WHO) has also given some safety guidelines. Big organizations such as OSHA have also provided some guidelines. Due to COVID-19 there it is expected that the labor costs may increase and investments in concrete industry may decrease. This paper will talk in detail about all the above-mentioned facts regarding COVID-19 and concrete construction.
\end{abstract}

Keywords: Civil Engineering, Concrete Construction, Construction, Coronavirus, COVID 19.

\section{INTRODUCTION}

1.1. What is Coronavirus Disease?

Coronavirus disease (COVID-19) is an infectious disease caused by a newly discovered coronavirus.

Most people infected with the COVID-19 virus experienced mild to moderate respiratory illness and recovered without requiring special treatment but older people, and those with underlying medical problems like cardiovascular disease, diabetes, chronic respiratory disease, and cancer are more likely to develop serious illness.

The best way to control and slow down transmission is to be well informed about the COVID-19 virus, the disease it causes and how it spreads. Protect oneself and others from infection by washing hands or using an alcohol based rub frequently and not touching one's face.

The COVID-19 virus spreads primarily through saliva droplets so it is best to cough in a flexed elbow so that the virus does not spread through droplets and make other people infected as well.

At this time, there are no specific vaccines or treatments for COVID-19 but there are many clinical trials ongoing and evaluating potential treatments. The World Health Organization (WHO) continues to provide updated information as soon as clinical findings become available [1].
1.2. CEMENT AND CONCRETE
The terms cement and concrete often are used
interchangeably, cement is actually an ingredient interchangeably, cement is actually an ingredient
of concrete. Concrete is a mixture of aggregates and paste. The aggregates are gravel or crushed stone and sand; the paste is water and Portland cement [2].

\section{SEVEN WAYS COVID-19 IS SHAPING CONSTRUCTION INDUSTRY}

\subsection{THE CLEANLINESS AND SAFETy oF Job Sites WiLl IMPROVE}

The COVID-19 pandemic has brought more seriousness to different factors of workers' health and safety within the industry. The emphasis on cleaner, less crowded work areas is one that won't recede even after the virus does. Construction firms will have to include a lot more health and safety measures so that employees are comfortable returning to work. They will be required to begin regular employee temperature checks, and top-to-bottom disinfections of sites, tools, and machinery. Some construction companies went even further with this. New job site policies have been introduced to improve safety such as employee temperature tests, staggered shifts, deep cleans, and the disinfection of job sites, equipment, and machinery.

"Employers can no longer conduct business the same way as they did in the past. Especially now, they need to be flexible and in many instances, creative, as they think of new ways to perform certain tasks that they have performed in the same way for many years in the past", stated attorney Michael Rubin, chair of Goldberg Segalla's national OSHA and Worksite Safety practice group [3]..

Construction firms will have to implement a variety of new protocols to promote employee health and social distancing, including a ban on carpooling, a 100\% mask and glove policy, and a well-stocked handwashing station.

\subsection{Technology Will Promote Social Distancing}

There would be fewer group activities and more clearly defined procedures and protocols for even some of the most mundane work tasks. The need for maintaining distance has also changed the way contractors communicate with customers and with project teams and companies have developed unique solutions to stay in touch.

Even after the coronavirus pandemic, social distancing on job sites across the whole word are likely to continue to some extent. The industries expect to see a reduced number of labor, 
group activities and more clarity in procedures and protocols, even for some of the simplest daily tasks.

Though the outbreak is subsiding in many areas, there will be measures in place to mitigate risk on construction sites going forward. The contractors would resort to remote technology for inspections, a trend that will continue even after the health crisis is over. It is opined that 360-degree photos and videos would form the daily progress reports.

Social distancing may not be so tough in the future as well, because technology companies have teamed up with the construction industry to develop and introduce innovative communication tools that can be used both on and off-site. An interactive web-based tool allowing clients to hold virtual public meetings has been created by LA-based AECOM [3].

In addition to this, building departments have been developing remote technology which will be used for inspections. These types of technologies are likely to rise in future.

\subsection{Increase in Time of Project Duration}

As a result of the new tech and health and safety measures that have been implemented into the industry, projects are expected to take considerably longer in favor of employee health. Suiting up with PPE and staggering shifts are just some of the new processes that will add considerable time to projects whilst on the other hand, increasing value. Besides, many of the major safety changes on construction sites will add to the time it takes to complete projects. While it is crucial to keep workers healthy, techniques such as suiting up with PPE, limited activities, and staggering work shifts will slow down progress, and the days of expediting a project may be over — at least for now.

"Construction schedules will not be the same as they used to be, things will take a little longer because we won't be able to have lots of people in the same place at the same time," stated Mike Benike, Executive Vice President at Rochester, USA [4].

It would be important for the contractors to consider time constraints when bidding out for new jobs. It should be made sure that the contract reflects a reasonable construction schedule. The entire project team, including owners, engineers, architects, and other partners, needs to understand that in the near future, projects will take longer than before to reach fruition.

\subsection{An Increase in Online Work}

With no option but to stay at home, many office employees will be running business operations via videoconferencing, emailing, and texting to stay in touch.

In numerous cases, working remotely will have benefits to both workers and construction companies that they were unable to see before. This could spark a trend of working remotely across the industry, making working away from the office more common.
Office employees in the construction industry have been asked and forced to stay at home in recent times. Workers have been relying on technology such as video conferencing from platforms like Zoom, Meets and Google Hangouts, and emailing to stay in touch and keep on top of business operations.

\subsection{Change in Project Demand Type Likely}

Projects that were set to be built by the end of this year have been reshaped by the coronavirus outbreak and may be affected for many years to come. Many hospitality, entertainment and retail projects are currently in much less demand whilst areas such as healthcare and healthcare-related manufacturing projects are seeing increase in activity. We've seen this in recent times with coronavirus hospitals being constructed in China in the space of a number of days, in addition to similar projects that have taken place in Moscow and in other cities across the planet.

This is set to be a short to mid-term change which is expected to turn to normal when the COVID-19 crisis vanishes. For now, though, demand changes combined with instability is set to become the norm.

The coronavirus outbreak has remodeled the types of projects that will be required this year and, perhaps, for many years to come. Retail, hospitality, and entertainment projects are likely to see decrease in demand while healthcare construction and healthcare-related manufacturing projects could see more activity.

\subsection{Supply-Chain will Recalibrate}

Coronavirus has made a major global supply chain disruption. Builders may be required to deal with delays and shortages of items like steel, surfacing and case goods.

\section{$2.7 \quad$ Increase in Off-Site Construction Techniques}

An increased focus on worker safety due to COVID-19 will help accelerate the industry move to off-site construction methods. Prefabrication and precasting, for example, is believed to be a gamechanger for the construction industry. The process reduces the amount of time you're required to be in the field, keeping the manpower in a controlled environment, proving to be conducive from a health standpoint.

The climate-controlled environment and assembly-line efficiency of factory production can decrease labor costs and condense project schedules, but the most important advantages like is increase in site safety, and reduced congestion will take center stage in post-pandemic construction [3][4].

\section{CURRENT SCENARIO OF THE CONSTRUCTION INDUSTRY WITH REGARDS TO SAFETY}

\subsection{What should construction companies do right now?}

- protect employees - have a plan of action to reduce exposure to COVID-19

- only the required employees should be asked to come when necessary depending on the project type and urgency

- review insurance policies

- establish staff rotations to decrease exposure

- review all contracts 
- consult with your lawyer, insurance agent, and financial advisor

\subsection{What should contractors do on their construction sites?}

- institute security procedures and requirements

- communicate with clients, with staff and with subcontractors

- document current conditions: video and photograph the site daily; use daily reports to track manpower both your own forces and trade contractors; keep track of who is working from home; monitor job progress carefully.

\subsection{What should contractors anticipate on their projects?}

- supply chain disruptions

- extended durations due to labor shortages and/or lower productivity

- increase in price for labor and materials

- delay in projects, suspensions, terminations

\subsection{How should contractors address these issues?}

- documentation

- discuss potential impacts with Owner in advance

- communicate with all stakeholders - Clients, Employees, Subcontractors, and your attorney, insurance agent and financial advisor

- update schedules

- Understand Force Majeure as well as Delay/Time Extension Provisions in Contracts and the triggering events for Force Majeure and other Delay/Time Extensions

- mitigate damages to the extent possible

It is critically important to understand the legal landscape as it may relate to potential claims, delays, suspensions and terminations.

- the attitudes of different Owners may vary

- plan how you will claim for impacts

- On Public Works Contract's understand any applicable regulations that may address: excusable delay, time extensions, changes, suspended work, stop work orders, termination, indemnification by the government, relaxing qualifications.

- understand that the failure to follow contractual terms could result in a waiver of Force Majeure remedies and subject you to delay damages and liquidated damages

Flexibility is important. Be prepared to negotiate with stakeholders on each project:

- remedies may vary in different contracts

- if work is disrupted, plan how to complete work and discuss with Owner

Evaluate steps contractually required to excuse performance and reserve remedies:

- give timely notice

- reduce effects of damages

- adhere to the contract's dispute resolution provisions

- be aware of any ongoing reporting and due diligence obligations [5].

\section{COVID-19, CONCRETE CONSTRUCTION AND} INDIA

On March 25, 2020, when the government announced the nationwide lockdown, almost all construction work was halted thereby leading to a crisis of livelihood of daily wage earners, forcing many of them to head to their homes. Their movement led to a crisis as the lockdown had entailed a shutting down of the country's transport infrastructure too [6].

After the phase 3 of the lockdown that began on May 4, the central government announced it would allow states to relax restrictions in certain areas provided they follow social distancing and workforce norms.

On a quarterly basis, the agency expects that there will be no demand for cement for Q1 continued by a slight increase through the seasonally weak Q2 will weigh on the sector's growth [7].

"This could be the first-ever demand contraction of this proportion for the cement sector in this fiscal" the report said [7].

While in Q3 key infra projects like roads, irrigation and metros will drive growth, only in Q4 of FY 21, the agency expects gradual pickup in urban belt as worker shortage [7].

A healthy price hike of Rs 25 per cement bag in fiscal 2020 coupled with lower commodity prices is expected to drive margins to a seven-year high in fiscal 2020 [7].

In the fiscal 2021, analysts expect the Ebitda margin to decrease by $100-125$ bps (basis points) and profitability of the cement companies might come under pressure, however the impact of demand freefall might be limited by lower input prices, the company said [7].

As per analysts, a full-fledged recovery will take much longer as the government's capex towards construction might come down, which accounts for $35-40 \%$ of cement demand as priority shifts to health and public welfare [7].

\subsection{Decrease in Construction Investment Due to COVID-19} Pandemic: KPMG [8].

COVID-19 pandemic will reduce investment in construction related projects in the range of 13 to $30 \%$ which will have significant impact on Gross Value Added (GVA) and employment in this sector, KPMG in India said in a report [8].

Construction-related GVA and employment is likely to reduce between 15 to $34 \%$ and 11 to $25 \%$ respectively when compared to pre-crisis projections for FY21, it said [8].

An investment of ₹ 1 lakh in the sector contributes ₹ 1.5 lakh for the GDP and generates ₹3.2 lakh as total revenues [8].

A survey conducted by KPMG indicates that labour costs for skilled workers are expected to increase by $20-25 \%$ while for the semi-skilled and unskilled workers the increase will be 10$15 \%[8]$.

While project implementation costs may not vary much for linear projects like irrigation canals, pipelines, transmission lines, roads, but for the non-linear projects, the cost may rise by $2-5 \%[8]$.

\section{COVID-19, CONCRETE CONSTRUCTION AND THE WORLD}

The major cement companies have identified that their first business risk from coronavirus begins from simply not having the labor to make building materials. LafargeHolcim, Switzerland's Chief Executive Officer Jan Jenisch summarized the group's action in its annual financial results 
for 2020 this week when he said, "We are taking all necessary measures to protect the health of our employees and their families." Other major cement producers that Global Cement has contacted have placed travel restrictions for staff and reduced access to production facilities [9].

The next risk for cement companies due to COVID- 19 comes from a decrease in economic activity. The Organization for Economic Co-operation and Development (OECD) predicts a global $0.5 \%$ year-on-year decrease in real gross domestic product (GDP) growth to $2.4 \%$, with China and India suffering the worst declines in GDP growth at around $1 \%$ and The global figure is the worst since the $-0.1 \%$ rate reported by the International Monetary Fund (IMF) in 2009 [9]. This forecast is contingent on the epidemic peaking in China in the first quarter of 2020 and new cases of the virus in other countries being sporadic and contained. So far the latter does not seem to have happened and the OECD's 'domino' scenario predicts a GDP reduction of $1.5 \%$. The OECD blamed the disease control measures in China, as well as the direct disruption to global supply chains, weaker final demand for imported goods and services and regional decrease in international tourism and business travel [9]. All of this is likely to drag on construction activity and demand for cement and concrete for some time to come.

The UK government, for example, is making its coronavirus action plan on an outbreak lasting four to six months. This could potentially happen in many countries throughout 2020. This has the potential to create a rolling effect of disruption as different nations are hit. Assuming that China has passed the peak of its local epidemic then its producers are likely to report decrease in income in the first quarter of 2020. The effect may even be reduced somewhat due to the existing winter peak shifting measures, where production is shut down to reduce pollution. Elsewhere, cement companies in the northern hemisphere may experience their busy summer months affected if the virus spreads [9].

Moving to cement markets and production, demand is likely to be slowed as countries implement various measures of isolation and quarantine leading to decrease in residential demand for buildings directly and as workforces are restricted. Business and infrastructure projects may follow as economies slow and governments refocus spending respectively [9].

The cement industry is also likely to encounter disruption to its supply chains. Major construction projects in South Asia are already reporting delays as Chinese workers have failed to return following quarantine restrictions after the Chinese New Year celebrations. On the production side, raw mineral supply tends to be local but fuels, like coal, often travel further. As other countries suffer uncontrolled outbreaks then similar travel restrictions may follow. Global Cement has yet to see any examples of materials in the cement industry supply chain being affected. Fuel markets may prove erratic as larger consumers cut back and suppliers like the Organization of the Petroleum Exporting Countries (OPEC) react by restricting production [9].
On the maintenance side cement plants need a wide array of parts such as refractories, motors, wear parts for mills, lubricants, gears, ball bearings and so forth. Some of these may have more complicated supply chain routes than they used to have 30 years ago. Chinese suppliers' reliance on using their own workers, for example, might well be a hindrance here until (or if) international quarantine rules are normalized. On the supplier side any new or upgrade plant project is vulnerable if necessary, parts are delayed by a production halt, logistics delayed and/or staff are prevented from visiting work sites. Other suppliers' weak points in their supply chains may become exposed in turn. This would benefit suppliers with sufficiently robust chains [9].

\section{COVID-19, CONCRETE CONSTRUCTION SAFETY AND OSHA}

The United States Department of Labor's Occupational Safety and Health Administration (OSHA) issued an alert listing steps employers can follow to implement social distancing in the workplace and to help protect workers from exposure to the coronavirus. Safety measures employers can implement include:

“• Isolate any worker who begins to exhibit symptoms until they can either go home or leave to seek medical care

- Establish flexible worksites (e.g., telecommuting) and flexible work hours (e.g., staggered shifts), if feasible

- Stagger breaks and re-arrange seating in common break areas to maintain physical distance between workers

- In workplaces where customers are present, mark six-foot distances with floor tape in areas where lines form, use drivethrough windows or curbside pickup, and limit the number of customers allowed at one time

- Move or reposition workstations to create more distance, and install plexiglass partitions

- Encourage workers to bring any safety and health concerns to the employer's attention" [10].

\subsection{Safety of construction workers During the COVID-19 Pandemic}

Every construction project is different and unique, and what is feasible and appropriate for any one project will depend on its unique characteristics. That said, the prevention tips that construction contractors may want to implement, include the following:

\subsection{General Safety rules and Policies}

- Any employee/contractor/visitor showing symptoms of COVID-19 will be asked to leave the jobsite and return home and get tested.

- Employees must avoid physical contact with each other and shall direct others (employees/contractors/visitors) to increase personal space to at least six (6) feet, where possible. Where work trailers are used, only necessary employees should enter the trailers and all employees should maintain social distancing while inside the trailers

- Safety meetings will be by telephone, if possible. If safety meetings are conducted in-person, attendance will be collected 
orally and the foreman/superintendent will sign-in each attendee. Attendance will not be tracked through passedaround sign-in sheets or mobile devices. During any in-person safety meetings, avoid meetings in groups of more than 10 people and participants must remain at least six (6) feet apart.

- All in-person meetings should be minimized to the extent possible and meetings will be conducted by telephone.

- The Company should understand that due to the nature of its work, access to running water for hand washing may be impracticable. In these situations, the Company should provide, if available, alcohol-based hand sanitizers and/or wipes.

- Employees will be encouraged to stagger breaks and lunches, if possible, to reduce the size of any group at any one time to less than ten (10) people.

- If possible, each employee should use/drive the same vehicle or piece of equipment every shift.

- Employees should limit the use of co-workers' tools and equipment to the extent that if tools must be shared, the Company will provide alcohol-based wipes to clean tools before and after use and when cleaning tools and equipment, consult manufacturing recommendations for proper cleaning techniques and restrictions.

- As part of the division of crews/staff, the Company will divide employees into dedicated shifts, at which point employees will remain with their dedicated shifts for the remainder of the project. If there is a legitimate reason for an employee to change shifts, the Company will have sole discretion in making that alteration.

- Employees are encouraged to limit the need for N95 respirator use, by using engineering and work practice controls to minimize dust. Such controls include the use of water delivery and dust collection systems, as well as limiting exposure time.

- The Company will divide crews/staff into two (2) groups where possible so that projects can continue working effectively in the event that one of the divided teams is required to quarantine.

- Employees are encouraged to minimize ride-sharing. While in vehicles, employees must ensure adequate ventilation.

- In lieu of using a common source of drinking water, such as a cooler, employees should use individual water bottles.

\subsection{Workers entering Homes and Occupied Building}

- During this work, employees must sanitize the work areas upon arrival, throughout the workday, and immediately before departure. The Company will provide alcohol-based wipes for this purpose.

- Construction and maintenance activities within occupied homes, office buildings, and other establishments, present unique hazards with regards to COVID-19 exposures. Everyone working within such establishments should evaluate the specific hazards when determining best practices related to COVID-19.

- The number of visitors to the job site, including the trailer or office, should be minimized to only those necessary for the work.

- Employees should ask other occupants to keep a personal distance of minimum six (6) feet at all times. Workers should wash or sanitize hands immediately before starting and after completing the work.

- All visitors should be screened in advance of arriving on the job site. If the visitor answers "yes" to any of the following questions, he/she should not be permitted to access the jobsite: o Have you been confirmed positive for COVID-19?

o Have you been in close contact with any persons who have been confirmed positive for COVID-19?

o Are you currently experiencing, or recently experienced, any acute respiratory illness symptoms such as fever, cough, or shortness of breath?

o Have you been in close contact with any persons who have travelled and are also exhibiting acute respiratory illness symptoms?

- Site deliveries should be permitted but should be properly coordinated in line with the employer's minimal contact and cleaning protocols. Delivery personnel should remain in their vehicles if at all possible.

\subsection{Personal Protective Equipment and Work Practice} Controls

- In addition to regular PPE for workers engaged in various tasks (fall protection, hard hats, hearing protection), the Company will also provide:

o Eye protection: Eye protection should be worn at all times while on-site.

o Gloves: Gloves should be worn at all times while on-site. The type of glove worn should be appropriate to the task. If gloves are not typically required for the task, then any type of glove is acceptable, including latex gloves. Employees should avoid sharing gloves.

o NOTE: The CDC is currently not recommending that healthy people wear N95 respirators to prevent the spread of COVID19. Nevertheless, employees should wear N95 respirators if required by the work and if available.

- Due to the current shortage of N95 respirators, the following Work Practice Controls should be followed:

o Dust should be kept down by using engineering and work practice controls, specifically through the use of water delivery and dust collection systems.

o Limit exposure time to the extent practicable.

o Isolate workers in dusty operations by using a containment structure or distance to limit dust exposure to those employees who are conducting the tasks, thereby protecting nonessential workers and bystanders. 
- Make a rigorous housekeeping program to reduce dust levels on the jobsite [11].

\section{CONCLUSION}

COVID-19 has brought, and will continue a major impact on concrete construction worldwide. The supply chains are disrupted due to lack of labor and complete lockdown in various countries. Declaring the novel coronavirus as a pandemic, governments around the globe have halted their industrial, commercial and domestic spheres in order to "break the chain". There are different ways in which COVID-19 is shaping the construction industry. There are certain measures which have been provided by the World Health Organization (WHO) which is being followed rigorously throughout the globe. Big organizations such as OSHA have also provided some guidelines.

On March 25, 2020, when the government announced the nationwide lockdown, almost all construction work was halted thereby leading to a crisis of livelihood of daily wage earners, forcing many of them to head to their homes. Their movement led to a crisis as the lockdown had entailed a shutting down of the country's transport infrastructure too.

After the phase 3 of the lockdown that began on May 4, the central government announced it would allow states to relax restrictions in certain areas provided they follow social distancing and workforce norms.

This pandemic has brought a lot of changes in the concrete construction industry like the cleanliness and safety of the job is going to increase to a very high level. The demand of projects would also change as the demand for hospitals is increasing at a rapid rate. Social distancing is going to be a key factor against COVID-19. There would be an increase in online work to maintain social distancing and the duration of projects may also increase due to decrease in production of concrete. There are certain norms set up by the government to fight against COVID-19. The World Health Organisation (WHO) has also given some safety guidelines.

\section{REFERENCES}

[1] World Health Organisation (WHO) website https://www.who.int/health-topics/coronavirus\#tab=tab_1

[2] PCA : Americas Cement Manufacturers website https://www.cement.org/cement-concrete-applications/cement-andconcrete-basics-faqs

[3] Dashore, A., Post-Pandemic View of Construction Sites, The Constructor website: https://theconstructor.org/construction/postpandemic-view-of-construction-sites/43251/

[4] Covid-19 Five Ways Pandemic Changing Construction, Construction Global website: https://www.constructionglobal.com/equipment-andit/covid-19-five-ways-pandemic-changing-construction

[5] Dulberg, M., Construction in the age of Pandemic, AZ Big Media Website : https://azbigmedia.com/real-estate/construction-in-the-ageof-the-pandemic/

[6] Rajput, V., Noida resumes construction of multiple projects amid Covid-19 pandemic, Hindustan Times Website. https://www.hindustantimes.com/india-news/noida-resumesconstruction-of-multiple-projects-amid-covid-19-pandemic/storyfBeisjwbGJPwVWUpCCq8aO.html

[7] Dilipkumar, B., India's cement demand may fall by 20-25 pc this fiscal if pandemic isn't contained by May: Crisil, Economic Times Website: https://economictimes.indiatimes.com/industry/indlgoods/svs/cement/indias-cement-demand-may-fall-by-20-25-pc-thisfiscal-if-pandemic-isnt-contained-by-maycrisil/articleshow/75009347.cms?utm_source=contentofinterest\&utm medium $=$ text\&utm_campaign $=$ cppst

[8] COVID-19 pandemic is likely to reduce investment in construction related projects : KPMG, The Hindu Website https://www.thehindu.com/business/covid-19-pandemic-is-likely-toreduce-investment-in-construction-related-projectskpmg/article31546351.ece

[9] Perilli, D., Cement and Coronavirus, Global Cement website : https://www.globalcement.com/news/item/10551-cement-and-thecoronavirus

[10] Editorial Staff, CBO., COVID-19 in Construction: Crucial Developments \& Updates, Construction Business Owner Website: https://www.constructionbusinessowner.com/covid19inconstruction

[11] Keeping Construction Workers Safe During the COVID-19 Pandemic, Associated General Contractors (AGC) website : https://www.agc.org/sites/default/files/Files/Safety\%20\%26\%20Healt h/Tips $\% 20$ for $\% 20$ Keeping $\% 20$ Construction $\% 20$ Workers $\% 20$ Safe $\% 2$ 0during\%20the\%20COVID-19\%20Pandemic.pdf 